\title{
Legionella shows a diverse secondary metabolism dependent on a broad spectrum Sfp-type phosphopantetheinyl transferase
}

\author{
Nicholas J Tobias ${ }^{1}$, Tilman Ahrendt ${ }^{1}$, Ursula Schell ${ }^{2}$, Melissa Miltenberger ${ }^{1}$, Hubert Hilbi ${ }^{2,3}$, Helge B \\ Bode Corresp. 1, $4^{-1}$ \\ 1 Fachbereich Biowissenschaften, Merck Stiftungsprofessur für Molekulare Biotechnologie, Goethe Universität, Frankfurt am Main, Germany \\ 2 Max von Pettenkofer Institute, Ludwig-Maximilians-Universität München, Munich, Germany \\ 3 Institute of Medical Microbiology, University of Zürich, Zurich, Switzerland \\ 4 Buchmann Institute for Molecular Life Sciences, Goethe Universität, Frankfurt am Main, Germany \\ Corresponding Author: Helge B Bode \\ Email address: h.bode@bio.uni-frankfurt.de
}

Several members of the genus Legionella cause legionnaires' disease, a potentially debilitating form of pneumonia. Studies frequently focus on the abundant number of virulence factors present in this genus. However, what is often overlooked, is the role of secondary metabolites from Legionella. Following whole genome sequencing, we assembled and annotated the Legionella parisiensis DSM 19216 genome. Together with 14 other members of the Legionella, we performed comparative genomics and analysed the secondary metabolite potential of each strain. We found that Legionella contains a huge variety of biosynthetic gene clusters that are potentially making a significant number of novel natural products with undefined function. Surprisingly, only a single Sfp-like phosphopantetheinyl transferase is found in all Legionella strains analyzed that might be responsible for the activation of all carrier proteins in primary (fatty acid biosynthesis) and secondary metabolism (polyketide and non-ribosomal peptide synthesis). Using conserved active site motifs, we predict some novel compounds that are probably involved in cell-cell communication, differing to known communication systems. We identify several gene clusters, which may represent novel signaling mechanisms and demonstrate the natural product potential of Legionella. 
$1 \quad$ Legionella shows a diverse secondary metabolism dependent on a broad

\section{spectrum Sfp-type phosphopantetheinyl transferase}

3 Nicholas J. Tobias ${ }^{1}$, Tilman Ahrendt ${ }^{1}$, Ursula Schell ${ }^{2}$, Melissa Miltenberger ${ }^{1}$, Hubert Hilbi ${ }^{3}$ \& Helge B.

Bode ${ }^{1,4}$

5

$6 \quad{ }^{1}$ Fachbereich Biowissenschaften, Merck Stiftungsprofessur für Molekulare Biotechnologie, Goethe-

7 Universität Frankfurt, Frankfurt am Main, Germany

$8{ }^{2}$ Ludwig-Maximilians University, Max von Pettenkofer Institute, Pettenkoferstr. 9a, 80336 Munich,

9 Germany

10

${ }^{3}$ University of Zürich, Institute of Medical Microbiology, Gloriastr. 30, 8006 Zürich, Switzerland

11

${ }^{4}$ Buchmann Institute for Molecular Life Sciences (BMLS), Goethe-Universität Frankfurt, Frankfurt am

Main, Germany

13

14 Corresponding author: Helge Bode

15 Email: h.bode@bio.uni-frankfurt.de

16

17 


\section{Abstract}

19 Several members of the genus Legionella cause legionnaires' disease, a potentially debilitating

20 form of pneumonia. Studies frequently focus on the abundant number of virulence factors

21 present in this genus. However, what is often overlooked, is the role of secondary metabolites

22 from Legionella. Following whole genome sequencing, we assembled and annotated the

23 Legionella parisiensis DSM 19216 genome. Together with 14 other members of the Legionella,

24 we performed comparative genomics and analysed the secondary metabolite potential of each

25 strain. We found that Legionella contains a huge variety of biosynthetic gene clusters that are

26 potentially making a significant number of novel natural products with undefined function.

27 Surprisingly, only a single Sfp-like phosphopantetheinyl transferase is found in all Legionella

28 strains analyzed that might be responsible for the activation of all carrier proteins in primary

29 (fatty acid biosynthesis) and secondary metabolism (polyketide and non-ribosomal peptide

30 synthesis). Using conserved active site motifs, we predict some novel compounds that are

31 probably involved in cell-cell communication, differing to known communication systems. We

32 identify several gene clusters, which may represent novel signaling mechanisms and demonstrate

33 the natural product potential of Legionella. 


\section{Introduction}

35 The genus of Legionella is relatively diverse with 58 member species, 29 of which are known to cause disease in humans (Cunha, Burillo \& Bouza, 2016). Legionellosis, infection with a member of the genus, can result in a form of pneumonia known as Legionnaires' disease or the less severe, flu-like disease known as Pontiac fever. The first Legionella was identified following an outbreak of Legionnaires' disease in 1976, and named Legionella pneumophila (Fraser et al., 2010). This species is responsible for a large proportion of Legionnaires' cases, can often require hospitalization and is particularly dangerous for immuno-compromised patients (Schlossberg \& Bonoan, 1998).

All Legionella spp. have a common association with water sources, surviving within amoebae, protozoa or slime moulds (Fields, Benson \& Besser, 2002). Their association within microbial biofilm communities is also beneficial for their ability to survive and cause disease (Chaabna et al., 2013; Khweek, Dávila \& Caution, 2014). This close association between bacteria and protozoan host has led to a number of horizontal gene transfer events, significantly contributing to the intracellular fitness of these bacteria (Chien et al., 2004; Cazalet et al., 2004; Gimenez et phagocytosis by eukaryotic cells, the bacteria are able to survive intracellularly, which is essential for disease progression.

55 Secondary metabolites are often small chemical compounds produced by a biosynthetic gene 56 cluster (BGC), often consisting of either PKS or NRPS. These compounds are often not essential 
57 for survival but might have significant roles in niche adaptation and virulence. Briefly, PKS and

58 NRPS are multifunctional enzymes that catalyze the condensation of carboxylic acid (PKS)

59 (Hertweck, 2009) or amino acid (NRPS) building blocks (Sieber \& Marahiel, 2005). PKS

60 catalyze the formation of $\mathrm{C}-\mathrm{C}$ bonds via the condensation of malonyl and acyl subunits that are

61 enzyme bound, as in the case of type I PKS, which show similar protein domain architecture to

62 eukaryotic fatty acid synthases. The catalytic functions of PKS and NRPS are organized in

63 modules, with each module responsible for the incorporation and processing of one individual

64 building block (different acyl or malonyl units for PKS or amino acids for NRPS). Due to these

65 similar biochemical principles, hybrids of PKS and NRPS are also possible (Du \& Shen, 2001).

66 The biosynthesis of PKS and NRPS derived natural products as well as fatty acids requires

67 specialized phosphopantetheinyl transferases (PPTases) that catalyze the post-translational

68 transfer of the 4'-phosphopantetheinyl group from coenzyme A (CoA) to acyl (ACP) or peptidyl

69 (PCP) carrier proteins also called thiolation (T) domains. These are components of the enzyme

70 complexes of fatty acid synthases (FAS), polyketide synthases (PKS) and nonribosomal peptide

71 synthetases (NRPS) (Mootz, Finking \& Marahiel, 2001; Mofid, Finking \& Marahiel, 2002) and

72 covalently link the biosynthesis intermediates to the enzyme complexes. PPTases in bacteria are

73 classified as AcpS (acyl carrier protein synthase) or Sfp (required for surfactin production in

74 Bacillus subtilis) enzymes and exhibit different substrate specificities. Sfp-PPTases are

75 monomeric enzymes of approximately 240 aa (Mofid, Finking \& Marahiel, 2002) that were

76 shown to activate all kinds of $\mathrm{T}$ domains from FAS, PKS and NRPS by attachment of a

77 phosphopantetheinyl group. AcpS PPTases on the other hand, are only half the size and are only

78 functional for ACPs from FAS and type II PKS (Gehring et al., 1997; Mootz, Finking \& 
79 Marahiel, 2001; Mofid, Finking \& Marahiel, 2002). Therefore, most bacteria (especially those

80 producing secondary metabolites) have two or more PPTases encoded in their genome.

81

82 The presence of PKS and NRPS is well established in all types of bacteria, for example,

83 Streptomyces, Mycobacteria, Myxobacteria, Pseudomonas and Bacillus. Often these products are

84 essential in a particular facet of their respective lifecycles. From Legionella, only four BGCs

85 have been explored in detail with three secondary metabolites structurally elucidated to date

86 (Figure 1) (Ahrendt et al., 2013; Shevchuk et al., 2014; Burnside et al., 2015; Johnston et al.,

87 2016a). Legioliulin (1), a product of a trans-AT PKS cluster first identified in L. dumoffii, was

88 reported originally in 2004 (Amemura-Maekawa et al., 2004) and biological activity assays

89 failed to determine a role for the compound beyond fluorescence (Ahrendt et al., 2013). This

90 study investigated the possibility that legioliulin is required for intracellular survival and

91 ultimately failed to assign a biological function. On the other hand, a transposon mutagenesis

92 library of L. pneumophila revealed a polyketide that interferes with lysosomal degradation

93 during infection of both protozoa and macrophages (Shevchuk et al., 2014). Legiobactin (2) is a

94 siderophore involved in iron sequestration (Cianciotto, 2007) and the unusual polyketide

95 legionellol A (3) is involved in sliding motility and might additionally act as a surfactant

96 (Johnston et al., 2016a). Despite all Legionella strains containing several BGCs, no further

97 research has explored the roles of their respective products. To attempt to further explore the

98 possibility that secondary metabolites are an important part of the Legionella lifecycle, we

99 performed genome-wide comparisons of 15 genome sequences from Legionella, paying

100 particular attention to the prevalence of BGCs. We explore possible structures and functions for

101 these BGCs. 
102

\section{Materials and Methods}

104 Culture conditions and DNA methods

105 The Legionella strains L. pneumophila JR32 (Sadosky, Wiater \& Shuman, 1993)and $\Delta i c m T$

106 (Segal \& Shuman, 1998), L. longbeachae NSW150 and L. parisiensis DSM 19216 were grown 107 in N-(2-acetamido)-2-aminoethanesulphonic acid (ACES) yeast extract (AYE) broth (Feeley et 108 al., 1979) or on buffered charcoal yeast extract agar (Difco, Detroit, USA) for 3 days at $37^{\circ} \mathrm{C} . E$. 109 coli BL21 Star (DE3) (Novagen) was cultured in LB medium supplemented with $40 \mu \mathrm{g} / \mathrm{mL}$ 110 kanamycin (Kan) and $100 \mu \mathrm{g} / \mathrm{mL}$ Ampicillin (Amp) (Carl Roth, Karlsruhe, Germany), if 111 necessary. Cells were harvested and DNA was extracted using the Puregene Yeast/Bacteria Kit B 112 (Qiagen) according to the manufacturer's recommendations.

113

114 Genome sequencing, assembly and annotation

115 Shotgun sequencing of Legionella parisiensis DSM 19216 was performed using a Genome 116 Sequencer FLX (Roche) by MWG Genomics (Munich). Assembly was performed using the 117 Celera Assembler (v5.3) and quality assessed using QUAST (Gurevich et al., 2013). Sequencing 118 yielded a total of 290,164 reads with average read length of $353 \mathrm{bp}$. The L. parisiensis genome 119 was assembled into a total of 226 contigs $(115>=1 \mathrm{~kb})$ with an N50 of 65,672 bp and a predicted 120 genomic coverage of 25. Genome annotation was performed using prokka (v1.12) (Seemann, 121 2014). Abricate was used to identify common antibiotic resistances

122 (https://github.com/tseemann/abricate).

123

124 Phylogenetic analysis 
125 Fourteen Legionella genomes were downloaded from NCBI (Table 1), their protein fasta files

126 extracted and together with L. parisiensis, ortholog families were identified using proteinortho5

127 (Lechner et al., 2011b). Protein singletons identified in only a single species were removed from

128 further analysis. The presence or absence of all ortholog families were used to generate a gene

129 content tree using the binary function associated with RAxML (Stamatakis, 2014) and the

130 gamma model of rate heterogeneity and a random number seed for parsimony inferences. Protein

131 sequences of the ACPs of E. coli (ACPS, WP_000986025.1) and Bacillus subtilis (Sfp-like,

132 WP_003234549.1) were taken from the NCBI website and used to identify homologs in each

133 species with Blastp. Protein sequences were aligned using ClustalW, and phylogenetic trees of

134 the PPTases were created using the PhyML plugin attached to Geneious (v6.1.6) (Guindon et al., 135 2010). Branch formation was supported with bootstrapping $(\mathrm{n}=1000)$.

136

137 Cloning and expression of LparPPTase

138 pCOLA_Duet1 (Novagen) was used as a vector for overproduction of the PPTase from $L$.

139 parisiensis. The PPTase gene was amplified using primers Lpar_PPtase_Fw_SacI

140 (GAGCTCGATGATCATTACCGAATTTAACCCT) and Lpar_PPtase_Rv_PstI

141 (GTTCTGAATTAGGGGCAACGTGTCGAC) (synthesized by Sigma-Aldrich, St. Louis, USA).

142 Both the PCR product obtained and pCOLA_Duet1 were digested with SacI and PstI

143 (Fermentas). Digestion products were separated by gel electrophoresis and desired fragments

144 isolated with Gene JETGel extraction kit (Fermentas). Isolated fragments were ligated for $1 \mathrm{~h}$ at

145 room temperature using T4-ligase (Fermentas). After ligation, E. coli DH10B was transformed

146 with the ligation mixtures in a $1 \mathrm{~mm}$ cuvette by electroporation at $1250 \mathrm{~V}, 200 \Omega$ and $25 \mu \mathrm{F}$.

147 Cells were plated on LB-Kan agar and incubated overnight at $37^{\circ} \mathrm{C}$. Colonies were picked and 
148 inoculated in LB-Kan media for plasmid extraction. The plasmids obtained were sequenced, and

149 pCOLA_LparPPTase plasmids transferred into E. coli BL21 Star. Positive colonies were picked

150 and cells were transformed with pUC18_indC (Brachmann et al., 2012) and grown on LB-Kan-

151 Amp agar. Cells were grown to an $\mathrm{OD}_{600}$ of 0.5 at $37^{\circ} \mathrm{C}$ at which time cultures were induced with

$1520.1 \mathrm{mM}$ isopropyl- $\beta$-D-thiogalactopyranoside (IPTG) (Fermentas), and the cultures were

153 incubated at $16^{\circ} \mathrm{C}$ overnight. Following induction of LparPPTase in pUC18_indC, cells were

154 pelleted and resuspended in deionized water for easy visualization of the blue pigment produced 155 by IndC.

156

157 Legionella in vivo inhibition.

158 L. parisiensis was grown to an $\mathrm{OD}_{600}$ of 0.1 in $200 \mu \mathrm{AYE}$ broth in a 96 -well plate at $37^{\circ} \mathrm{C}$.

159 Putative PPTase inhibitors 4-6 (Foley et al., 2014) were then added in different concentrations,

160 and the cells were allowed to grow for 24 hours. For visualization of legioliulin production in $L$.

161 parisiensis, the cells were illuminated with long-wave UV-light. The MIC of the PPTase

162 inhibitors were tested in triplicate on L. parisiensis, L. pneumophila and L. longbeachae using

163 the $\mathrm{OD}_{600}$ value.

164

165 Secondary metabolite identification

166 Secondary metabolites were identified using antiSMASH 3.0 (Weber et al., 2015a) with the

167 option ClusterFinder algorithm activated. The results from each genome were then aligned using

168 Mauve (Darling et al., 2004), a BLAST based analysis program, to identify homologous clusters.

169 Using this method, we assembled some clusters that were split across different contigs by

170 sequence similarity, additionally taking into account the predicted substrate specificities and 
171 domain modifications from each unassembled module. The sequence for the isocyanide synthase

172 cluster, isnAB, was taken from Xenorhabdus nematophila (Crawford et al., 2012) and identified

173 in Legionella species using BLASTp (v2.2.29) as a part of the BLAST+ suite (Camacho et al.,

174 2009).

175

176 Results

177 Genome of L. parisiensis

178 Purified genomic DNA from L. parisiensis DSM 19216 was used for shotgun sequencing.

179 Assembly using Celera (v5.3) revealed a 4,232,283 bp genome with a GC content of $37.98 \%$ and

180 was predicted to contain 3,916 protein-coding sequences (CDS). This Whole Genome Shotgun

181 project has been deposited at GenBank under the accession number LSOG00000000. The

182 version described in this paper is version LSOG01000000.

183

184 Genome wide analyses

185 Together with the 14 other Legionella genomes (Table 1) we identified all protein ortholog 186 families in Legionella (Supplementary Table 1). The core genome of the 15 Legionella species 187 consists of 711 coding sequences and includes a type II secretion system as well as the Dot/Icm 188 system. The conserved type II secretion system is essential for intracellular survival and growth 189 (Hales \& Shuman, 1999; Polesky et al., 2001; Rossier, Starkenburg \& Cianciotto, 2004) as well 190 as promoting growth at low temperatures (Söderberg, Rossier \& Cianciotto, 2004). The Dot/Icm 191 system is already known to be ubiquitous in all strains (Feldman et al., 2005). The effectors 192 secreted by this system work in concert to evade the phagosome and form the Legionella- 
193 containing vacuole allowing the bacteria to grow intracellularly (Isberg, O'Connor \& Heidtman,

194 2009; Ensminger, 2016).

195

196 Using the program abricate, we additionally analysed the genomes for possible antibiotic

197 resistance genes. In L. anisa, L. cherrii, L. longbeachae, L. sainthelensis and L. wadsworthii

198 beta-lactamase resistance was identified with no other antibiotic resistance genes present.

199 However, several multi drug efflux pumps were also found in the genomes (Supplementary

200 Table 2). Using the amino acid sequences of all annotated coding sequences from each strain, we

201 determined ortholog families using proteinortho5 (Lechner et al., 2011a). From these ortholog

202 families, we produced a phylogeny representing the gene content based upon the presence or

203 absence of each protein ortholog family. Following analysis of all Legionella strains and their

204 BGCs, we constructed a map of each BGC common to more than a single species based on the

205 protein sequence identity (Figure 2, Figure 3). Bacteriocins are a class of ribosomally

206 synthesized peptides with antibacterial properties. They are classified based on their mode of

207 action and size (Yang et al., 2014) and are typically used to attack other bacteria competing in

208 similar environments (or sometimes have broad-spectrum activity) but contain resistance

209 mechanisms to avoid self-harm (Cotter, Hill \& Ross, 2005). This analysis revealed that there is a

210 range of different bacteriocins present in Legionella with all species containing at least one

211 cluster with L. geestiana, L. oakridgensis and L. shakespearei containing bacteriocins not present

212 in any other species (Figure 2, Supplementary Figure 1, Supplementary Table 3).

213

214 Only a single PPTase was identified in Legionella, which activates natural product biosynthesis

215 clusters in vitro. 
216 Interestingly, the ortholog analysis identified only a single Sfp-like phosphopantetheinyl

217 transferase (PPTase) in all of the analyzed Legionella genomes (Figure 4). No AcpS-like

218 PPTase that is usually involved in fatty acid biosynthesis exists (Mofid, Finking \& Marahiel, 219 2002). PPTases are required to post-translationally attach a 4'-phosphopantetheine arm from 220 CoA to the serine residue contained in the thiolation (acyl carrier protein (ACP) or peptidyl 221 carrier protein (PCP)) domain and therefore are essential for fatty acid, polyketide and non222 ribosomal peptide biosynthesis (Walsh et al., 1997; Stack, Neville \& Doyle, 2007).

223 Unsurprisingly, within this group, Legionella PPTases form a distinct branch (Figure 4). To test 224 if the L. parisiensis Sfp-like PPTase could activate a NRPS, IndC from Photorhabdus 225 luminescens (Brachmann et al., 2012) and the PPTase from L. parisiensis were co-produced in E. 226 coli BL21 Star. IndC produces the blue pigment indigoidine by condensation of two glutamines.

227 While indC is constitutively expressed in this experiment, the L. parisiensis PPTase gene 228 expression was under control of an IPTG-inducible promoter. Addition of IPTG and consequent 229 PPTase expression led to blue pigment production (Supplementary Figure 2A). As the E. coli 230 Sfp-type PPTase, EntD, is not capable of activating IndC (Brachmann et al., 2012), any

231 production of indigoidine must be activated by the PPTase from L. parisiensis. Harvesting and 232 resuspension of the colored cells in water shows a bright blue pigmentation of the IPTG-induced 233 culture (Supplementary Figure 2B).

235 Inhibition of legioliulin production and growth in L. parisiensis

236 To rule out the possibility that any PPTase was missed in this analysis, we used 2-pyridinyl- $N$ -

237 (4-aryl)-piperazine-1-carbothioamides (4-6), specific inhibitors of bacterial Sfp-like PPTases

238 (Foley et al., 2014), to shut off legioliulin production. Legioliulin production and growth are 
239 closely linked. Bacterial growth was measured at $\mathrm{OD}_{600}$, and legioliulin production was observed

240 under long-wave UV-light. The addition of $1 \mu \mathrm{g} / \mathrm{mL}$ of inhibitor 4 resulted in a total loss of

241 legioliulin production. We then used different concentrations of 4 to determine substance

242 effectivity (Figure 5). Concentrations as low as $0.4 \mu \mathrm{g} / \mathrm{mL}$ of 4 showed an inhibition in

243 legioliulin biosynthesis and growth. For compounds $\mathbf{5}$ and 6, initial inhibitory effects were

244 observed at concentrations of 0.75 and $6 \mu \mathrm{g} / \mathrm{mL}$, respectively. Similarly, growth inhibition was

245 observed for L. pneumophila and L. longbeachae (Supplementary Table 3).

246

247 Biosynthetic gene clusters

248 During the secondary metabolite analysis, we used antiSMASH to predict BGCs and extracted

249 all those containing predicted siderophore, PKS, NRPS, lantipeptide or bacteriocin clusters. With

250 the optional ClusterFinder algorithm activated (Cimermancic et al., 2014), we also examined all

251 putative and saccharide-like clusters for misclassification (Supplementary Table 3). Strains

252 contained between 15 and 36 BGCs in total with NRPS clusters being the most prevalent. The

253 most widespread PKS, NRPS and siderophore clusters found in Legionella are shown in Figure 3

254 highlighting the overall synteny as well as the domain architecture of the natural product

255 synthases.

256

257 Non-ribosomal peptide synthetase product predictions in Legionella

258 PKS and NRPS specificity can often be predicted based upon the DNA sequence and

259 comparisons to experimentally validated studies (Stachelhaus, Mootz \& Marahiel, 1999; Challis,

260 Ravel \& Townsend, 2000; Yadav, Gokhale \& Mohanty, 2003). In the case of the Stachelhaus

261 code, conserved motifs in the adenylation (A) domain are used to predict substrate specificity. 
262 These conserved motifs and their respective specificities were confirmed by single nucleotide

263 mutations resulting in either a loss of, or relaxation of substrate specificity (Stachelhaus, Mootz

264 \& Marahiel, 1999). Prediction using a hidden Markov model based approach is also available to

265 predict specificities of either A domains from NRPS or acyltransferase (AT) domains from PKS

266 and is integrated into antiSMASH (Minowa, Araki \& Kanehisa, 2007; Weber et al., 2015b).

267 NRPSPredictor2, unlike the previous two methods, uses a support vector machine to predict

268 specificities (Röttig et al., 2011). These methods formed the basis to predict the structures of the 269 natural products produced by BGCs in Legionella. In many Legionella BGCs, the specificities

270 for A domains involved in the activation of the correct amino acid in the NRPS could either not

271 be predicted or showed variable results when these different algorithms were used. We therefore

272 only attempted to predict resulting structures where a consensus among the three methods was

273 reached. Several low molecular weight natural products produced from monomodular NRPS

274 could be predicted assuming non-iterative use of these NRPS modules (Figure 6).

275

276 Discussion

277 Secondary metabolism in Legionella is under-pinned by a broad spectrum PPTase

278 Following the sequencing of the L. parisiensis genome, we noted the presence of 32 BGCs, as

279 predicted by antiSMASH (Supplementary Table 3). We then further investigated a selection of

280 other Legionella strains to obtain a snapshot of the secondary metabolite potential of the genus.

281 Through ortholog clustering we looked specifically for genes that are known to be essential in

282 secondary metabolism.

283 Interestingly, this diversity in secondary metabolites gene clusters appeared to be controlled by a 284 single Sfp-like PPTase in all Legionella strains analyzed, L.Ppt (Legionella PPTase, Figure 4). 
285 This PPTase may therefore be capable of activating all different carrier proteins involved in 286 polyketide and non-ribosomal peptide biosynthesis as well as fatty acid biosynthesis, a part of

287 the primary metabolism as has been seen before (Losick \& Isberg, 2006). A precedent for this 288 has been made in Pseudomonas aeruginosa, which carries only a single broad spectrum PPTase 289 that is active in both primary and secondary metabolism (Seidle, Couch \& Parry, 2006).

290 However, the veracity of this hypothesis is yet to be definitively determined in Legionella.

291 Following identification of only one PPTase, we used an indigoidine production assay to confirm 292 a role for L.Ppt from L. parisiensis in secondary metabolism. The enzyme was able to activate 293 the NRPS IndC from P. luminescens, even though no NRPS product is known for any Legionella 294 strain so far confirming this function. To investigate the effect on suppression of the Sfp-type 295 PPTase, we grew L. parisiensis in the presence of Sfp-type PPTase inhibitors (Foley et al., 2014) 296 and showed that legioliulin production, in addition to cell viability, is halted (Supplementary 297 Table 4, Figure 5). The importance of this is that if only a single PPTase controls both primary 298 and secondary metabolism, PPTase inhibitors may be effective as monotherapeutic drugs with 299 multi-target effects (Silver, 2007) resulting from the loss of several functional ACP or PCP 300 proteins, inhibiting essential fatty acid and secondary metabolite biosynthesis. Although fatty 301 acid biosynthesis has been questioned as a general target for antibiotic therapy (Parsons \& Rock, 302 2011), the parallel inhibition of fatty acid, virulence factor and signaling compound biosynthesis 303 might make PPTase inhibitors powerful antibiotics or drugs that could also work against 304 intracellular pathogens, where fatty acid biosynthesis is essential (Yao et al., 2014). 305

306 Reconstruction of BGCs and ortholog clustering highlight the diversity of potential secondary 307 metabolites in Legionella 
308 Only the structures of legioliulin (1), legiobactin (2) and legionellol (3) have been solved (Figure

309 1) while one other PKS derived compound has been implicated in lysosomal degradation

310 (Shevchuk et al., 2014). Legioliulin is a trans-AT PKS derived fluorophore (Figure 3A).

311 However, beyond fluorescence of bacterial strains containing the gene cluster, a biological

312 function was not defined for legioliulin. This is perhaps unsurprising given that only the strains

313 amoebic intracellular growth capabilities were tested while the species has been isolated from

314 both environmental and clinical sources in both fluorescing and non-fluorescing forms (Igel,

315 Helbig \& Lück, 2004). The cluster of coding sequences responsible for legionellol, a hydrophilic

316 molecule involved in lipid scaffolding, has been ascribed to a number of small discrete genes

317 (lpg2223-41) coding for different domains in L. pneumophila (Supplementary Figure 3)

318 (Johnston et al., 2016b).

320 One disadvantage with short read sequencing technologies is that long gene sequences that are

321 prone to containing repetitive sequences may not be properly assembled. This may be the case

322 for the PKS and NRPS gene clusters that we have examined here, as some are known to be

323 highly repetitive such as the mycolactone PKS(Stinear et al., 2004) or the syringopeptin NRPS

324 (Scholz-Schroeder, Soule \& Gross, 2007). Although Legionella probably do not contain

325 examples as extreme as mycolactone or syringopeptin, it is possible that the misclassified

326 saccharide-like clusters or some of the contigs containing clusters at their respective termini are

327 in fact collapsed BGCs due to poor assembly. Despite this, we found significant conservation of

328 some BGCs, although this was not always reflected in the phylogenetic tree composed of all

329 coding sequences. For example, Cluster F (Figure 2) is present in species that appear more

330 dissimilar with respect to their gene content. This observation may be in part explained by the 
331 amount of horizontal gene transfer that is reported to occur in this genus leading to a greater

332 diversity of coding sequences (Gomez-Valero et al., 2011).

333

334 Cluster $\mathrm{F}$, the most prevalent cluster, is a NRPS consisting of a single module containing an A, T

335 and $\mathrm{C}$ domain, however it was not limited to a given clade of bacteria suggesting it is probably

336 either dispensable for growth and survival, or it plays a more general role. Perhaps more

337 interesting are the clusters that are exclusive to certain clades such as clusters E and $\mathrm{K}$, a NRPS

338 and type III PKS, respectively as well as clusters $\mathrm{M}$ and N, which are both siderophores. The

339 apparent maintenance of these clusters in specific clades may be representative of essential

340 functions in their particular environment. However, experimental evidence is needed to verify

341 the veracity of this hypothesis. Siderophores are a well-known virulence factor of many bacteria

342 and the structure of legiobactin (2) has already been elucidated in L. pneumophila (Cluster M,

343 (Burnside et al., 2015)). It is reported as having an identical structure to rhizoferrin (Drechsel et

344 al., 1991; Burnside et al., 2015) and is essential for ferric iron uptake during infection of the

345 lungs (Liles, Scheel \& Cianciotto, 2000; Robey \& Cianciotto, 2002; Allard et al., 2009; Chatfield

346 et al., 2012).

348 Several Legionella strains also encode homologs of $i s n A$ and isnB that have been shown to be

349 involved in the biosynthesis of isonitrile containing natural products that are widespread among

350 bacteria (Brady et al., 2007). Specifically, isnA and isnB encode proteins that, together, produce

351 an inhibitor of insect phenoloxidase that has been shown to be important in defense against host

352 immune responses in entomopathogenic bacteria (Brady et al., 2007; Crawford et al., 2012). In

353 Legionella, a helix-turn-helix domain protein and a cytochrome P450 oxidase are always 
354 associated with the cluster (Figure 3L). In Pseudomonas, the isnAB cluster is part of a larger

355 BGC and does not make the phenoloxidase inhibitor. There, the IsnAB homologs PvcA and

$356 \mathrm{PvcB}$ are encoded as a part of the pyoverdine BGC where they are involved in maturation of the

357 siderophore pyoverdine (Drake \& Gulick, 2008).

358

359 Analysis of clusters B-D reveals the presence of NRPS that are clustered with genes encoding a 360 transcriptional regulator. Although not definitive, this provides evidence supporting a role for

361 these products as novel signaling compounds as seen in other Gram-negative bacteria

362 (Brachmann et al., 2013; Brameyer et al., 2015). If this is indeed the case, its significance lies in

363 the fact that the bacteria occupy a relatively diverse environment and the signals may be specific

364 for their respective niches.

365

366 In addition to the more conserved clusters found in several strains, unique clusters have been 367 identified that are present only in individual strains (Supplementary Figure 3). Among them is 368 another trans-AT PKS in L. cherii that might be responsible for the described red fluorescence of 369 this strain that also gave it its name. However, the red fluorescence might also be derived from

370 the legioliulin cluster, also encoded in this genome, when a starting unit other than cinnamic acid

371 is used that could result in a red-shift of the resulting fluorophore. Different PKS/NRPS hybrids

372 are encoded in L. anisa, L. parisiensis and L. longbeachae that additionally encode type I PKSs

373 that could also be involved in the production of unusual fatty acids or lipids required for their

374 particular niche (Supplementary Figure 3).

375 
376 There are a large number of diverse and interesting BGCs in Legionella that have thus far been

377 unexplored. Although few are conserved across species, we cannot rule out the possibility that

378 these BGCs are providing important chemical compounds to their respective strains, whether for

379 signaling, or otherwise. The lack of cluster conservation further reinforces the notion that this

380 genus is a large, untapped reservoir for novel secondary metabolite discovery. Given the

381 association of these bacteria with protozoa in the environment and the interaction of the

382 pathogenic strains with human phagocytic cells, bioactive metabolites originating from this

383 genus may have activity against eukaryotic targets making this an interesting area of future

384 research.

385

386 Availability of supporting data

387 Supplementary Table 1 - ortholog families identified in 15 Legionella spp.

388 Supplementary Table 2 - List of coding sequences mentioned in the text and their ortholog in

389 each species

390 Supplementary Table 3 - Complete list of BGCs

391 Supplementary Table 4 - Growth inhibition of L. parisiensis, L. pneumophila and L.

392 longbeachae with Sfp-type PPTase inhibitors 4-6.

393 Supplementary Figure 1 - Cluster organization of clusters O-U

394 Supplementary Figure 2 - Indigoidine assay

395 Supplementary Figure 3 - Other clusters unique to some Legionella

396

397 List of abbreviations

398 PKS - polyketide synthase 
399 NRPS - non-ribosomal peptide synthetase

400 BGC - biosynthetic gene cluster

401 AT - acyltransferase

402 A - adenylation

$403 \mathrm{~T}-$ thiolation

$404 \mathrm{C}-$ condensation

405 TE - thioesterase

406

407

408 Acknowledgements

409 The authors are grateful to David J. Maloney for samples of PPTase inhibitors 4-6.

410

411

412

413 
414

415

416

417

418

419

420

421

422

423

424

425

426

427

428

429

430

431

432

433

434

435

436

437

438

439

440

441

442

443

444

445

446

447

448

449

450

451

452

453

454

455

456

457

458

\section{References}

Ahrendt T, Miltenberger M, Haneburger I, Kirchner F, Kronenwerth M, Brachmann AO, Hilbi H, Bode HB 2013. Biosynthesis of the Natural Fluorophore Legioliulin from Legionella. Chembiochem : a European journal of chemical biology 14:1415-1418. DOI: 10.1002/cbic. 201300373.

Allard KA, Dao J, Sanjeevaiah P, McCoy-Simandle K, Chatfield CH, Crumrine DS, Castignetti D, Cianciotto NP 2009. Purification of Legiobactin and importance of this siderophore in lung infection by Legionella pneumophila. Infection and immunity 77:2887-2895. DOI: 10.1128/IAI.00087-09.

Amemura-Maekawa J, Hayakawa Y, Sugie H, Moribayashi A, Kura F, Chang B, Wada A, Watanabe H 2004. Legioliulin, a new isocoumarin compound responsible for blue-white autofluorescence in Legionella (Fluoribacter) dumoffii under long-wavelength UV light. Biochemical and Biophysical Research Communications 323:954-959. DOI: 10.1016/j.bbrc.2004.08.180.

Brachmann AO, Brameyer S, Kresovic D, Hitkova I, Kopp Y, Manske C, Schubert K, Bode HB, Heermann R 2013. Pyrones as bacterial signaling molecules. Nature chemical biology 9:573-578. DOI: 10.1038/nchembio.1295.

Brachmann AO, Kirchner F, Kegler C, Kinski SC, Schmitt I, Bode HB 2012. Triggering the production of the cryptic blue pigment indigoidine from Photorhabdus luminescens. Journal of biotechnology 157:96-99.

Brady, John D Bauer, Michael F Clarke-Pearson A, Daniels R 2007. Natural Products from isnAContaining Biosynthetic Gene Clusters Recovered from the Genomes of Cultured and Uncultured Bacteria. American Chemical Society. DOI: 10.1021/ja075492v.

Brameyer S, Kresovic D, Bode HB, Heermann R 2015. Dialkylresorcinols as bacterial signaling molecules. Proceedings of the National Academy of Sciences of the United States of America 112:572-577. DOI: 10.1073/pnas.1417685112.

Brenner DJ, Steigerwalt AG, Gorman GW, Wilkinson HW, Bibb WF, Hackel M, Tyndall RL, Campbell J, Feeley JC, Thacker WL, Skaliy P, Martin WT, Brake BJ, Fields BS, Mceachern HV, Corcoran LK 1985. Ten New Species of Legionella. International journal of systematic and evolutionary microbiology 35:50-59. DOI: 10.1099/00207713-35-1-50.

Bruner SD, Weber T, Kohli RM, Schwarzer D, Marahiel MA, Walsh CT, Stubbs MT 2002. Structural Basis for the Cyclization of the Lipopeptide Antibiotic Surfactin by the Thioesterase Domain SrfTE. Structure 10:301-310. DOI: 10.1016/S0969-2126(02)00716-5.

Brzuszkiewicz E, Schulz T, Rydzewski K, Daniel R, Gillmaier N, Dittmann C, Holland G, Schunder E, Lautner M, Eisenreich W, Lück C, Heuner K 2013. Legionella oakridgensis ATCC 33761 genome sequence and phenotypic characterization reveals its replication capacity in amoebae. International Journal of Medical Microbiology 303:514-528. DOI: 10.1016/j.jjmm.2013.07.003.

Burnside DM, Wu Y, Shafaie S, Cianciotto NP 2015. The Legionella pneumophila Siderophore Legiobactin Is a Polycarboxylate That Is Identical in Structure to Rhizoferrin. Infection and immunity 83:3937-3945. DOI: 10.1128/IAI.00808-15.

Camacho C, Coulouris G, Avagyan V, Ma N, Papadopoulos J, Bealer K, Madden TL 2009. BLAST+: architecture and applications. BMC Bioinformatics 10:421. DOI: 10.1186/14712105-10-421.

Campbell J, Bibb WF, Lambert MA, Eng S, Steigerwalt AG, Allard J, Moss CW, Brenner DJ 
462

463

464

465

466

467

468

469

470

471

472

473

474

475

476

477

478

479

480

481

482

483

484

485

486

487

488

489

490

491

492

493

494

495

496

497

498

499

500

501

502

503

504

1984. Legionella sainthelensi: a new species of Legionella isolated from water near Mt. St. Helens. Applied and environmental microbiology 47:369-373.

Cazalet C, Gomez-Valero L, Rusniok C, Lomma M, Dervins-Ravault D, Newton HJ, Sansom FM, Jarraud S, Zidane N, Ma L, Bouchier C, Etienne J, Hartland EL, Buchrieser C 2010. Analysis of the Legionella longbeachae genome and transcriptome uncovers unique strategies to cause Legionnaires' disease. PLoS genetics 6:e1000851. DOI: 10.1371/journal.pgen.1000851.

Cazalet C, Rusniok C, Brüggemann H, Zidane N, Magnier A, Ma L, Tichit M, Jarraud S, Bouchier C, Vandenesch F, Kunst F, Etienne J, Glaser P, Buchrieser C 2004. Evidence in the Legionella pneumophila genome for exploitation of host cell functions and high genome plasticity. Nature Genetics 36:1165-1173. DOI: 10.1038/ng1447.

Chaabna Z, Forey F, Reyrolle M, Jarraud S, Atlan D, Fontvieille D, Gilbert C 2013. Molecular diversity and high virulence of Legionella pneumophila strains isolated from biofilms developed within a warm spring of a thermal spa. BMC microbiology 13:17. DOI: 10.1186/1471-2180-13-17.

Challis GL, Ravel J, Townsend CA 2000. Predictive, structure-based model of amino acid recognition by nonribosomal peptide synthetase adenylation domains. Chemistry \& biology 7:211-224. DOI: 10.1016/S1074-5521(00)00091-0.

Chatfield CH, Mulhern BJ, Viswanathan VK, Cianciotto NP 2012. The major facilitator superfamily-type protein $\mathrm{LbtC}$ promotes the utilization of the legiobactin siderophore by Legionella pneumophila. Microbiology 158:721-735. DOI: 10.1099/mic.0.055533-0.

Chien M, Morozova I, Shi S, Sheng H, Chen J, Gomez SM, Asamani G, Hill K, Nuara J, Feder M, Rineer J, Greenberg JJ, Steshenko V, Park SH, Zhao B, Teplitskaya E, Edwards JR, Pampou S, Georghiou A, Chou IC, Iannuccilli W, Ulz ME, Kim DH, Geringer-Sameth A, Goldsberry C, Morozov P, Fischer SG, Segal G, Qu X, Rzhetsky A, Zhang P, Cayanis E, De Jong PJ, Ju J, Kalachikov S, Shuman HA, Russo JJ 2004. The Genomic Sequence of the Accidental Pathogen Legionella pneumophila. Science (New York, N.Y.) 305:1966-1968. DOI: $10.1126 /$ science. 1099776.

Cianciotto NP 2007. Iron Acquisition by Legionella pneumophila. Biometals 20:323-331. DOI: 10.1007/s10534-006-9057-4.

Cimermancic P, Medema MH, Claesen J, Kurita K, Wieland Brown LC, Mavrommatis K, Pati A, Godfrey PA, Koehrsen M, Clardy J, Birren BW, Takano E, Sali A, Linington RG, Fischbach MA 2014. Insights into Secondary Metabolism from a Global Analysis of Prokaryotic Biosynthetic Gene Clusters. Cell 158:412-421. DOI: 10.1016/j.cell.2014.06.034.

Cotter PD, Hill C, Ross RP 2005. Bacteriocins: developing innate immunity for food. Nature reviews. Microbiology 3:777-788. DOI: 10.1038/nrmicro1273.

Crawford JM, Portmann C, Zhang X, Roeffaers MBJ, Clardy J 2012. Small molecule perimeter defense in entomopathogenic bacteria. Proceedings of the National Academy of Sciences of the United States of America 109:10821-10826. DOI: 10.1073/pnas.1201160109.

Cunha BA, Burillo A, Bouza E 2016. Legionnaires' disease. The Lancet 387:376-385. DOI: 10.1016/S0140-6736(15)60078-2.

Darling ACE, Mau B, Blattner FR, Perna NT 2004. Mauve: multiple alignment of conserved genomic sequence with rearrangements. Genome research 14:1394-1403. DOI: 10.1101/gr.2289704.

Dennis PJ, Brenner DJ, Thacker WL, Wait R, Vesey G, Steigerwalt AG, Benson RF 1993. Five 
505

506

507

508

509

510

511

512

513

514

515

516

517

518

519

520

521

522

523

524

525

526

527

528

529

530

531

532

533

534

535

536

537

538

539

540

541

542

543

544

545

546

547

548

549

550

New Legionella Species Isolated from Water. International journal of systematic and evolutionary microbiology 43:329-337. DOI: 10.1099/00207713-43-2-329.

Drake EJ, Gulick AM 2008. Three-dimensional Structures of Pseudomonas aeruginosa PvcA and PvcB, Two Proteins Involved in the Synthesis of 2-Isocyano-6,7-dihydroxycoumarin. Journal of molecular biology 384:193-205.

Drechsel H, Metzger J, Freund S, Jung G, Boelaert JR, Winkelmann G 1991. Rhizoferrin - a novel siderophore from the fungus Rhizopus microsporus var. rhizopodiformis. Biology of metals 4:238-243. DOI: 10.1007/BF01141187.

Du L, Shen B 2001. Biosynthesis of hybrid peptide-polyketide natural products. Current opinion in drug discovery \& development 4:215-228.

Edelstein PH, Brenner DJ, Moss CW, Steigerwalt AG, FRANCIS EM, GEORGE WL 1982. Legionella wadsworthii Species Nova: A Cause of Human Pneumonia. Annals of Internal Medicine 97:809-813. DOI: 10.7326/0003-4819-97-6-809.

Ensminger AW 2016. Legionella pneumophila, armed to the hilt: justifying the largest arsenal of effectors in the bacterial world. Current Opinion in Microbiology 29:74-80. DOI: 10.1016/j.mib.2015.11.002.

Feeley JC, Gibson RJ, Gorman GW, Langford NC, Rasheed JK, Mackel DC, Baine WB 1979. Charcoal-yeast extract agar: primary isolation medium for Legionella pneumophila. Journal of clinical microbiology 10:437-441.

Feldman M, Zusman T, Hagag S, Segal G 2005. Coevolution between nonhomologous but functionally similar proteins and their conserved partners in the Legionella pathogenesis system. Proceedings of the National Academy of Sciences 102:12206-12211. DOI: 10.1073/pnas.0501850102.

Felnagle EA, Jackson EE, Chan YA, Podevels AM, Berti AD, McMahon MD, Thomas MG 2008. Nonribosomal Peptide Synthetases Involved in the Production of Medically Relevant Natural Products. Molecular Pharmaceutics 5:191-211. DOI: 10.1021/mp700137g.

Fields BS, Benson RF, Besser RE 2002. Legionella and Legionnaires' disease: 25 years of investigation. Clinical microbiology reviews 15:506-526. DOI: 10.1128/CMR.15.3.506526.2002.

Foley TL, Rai G, Yasgar A, Daniel T, Baker HL, Attene-Ramos M, Kosa NM, Leister W, Burkart MD, Jadhav A, Simeonov A, Maloney DJ 2014. 4-(3-Chloro-5(trifluoromethyl)pyridin-2-yl)-N-(4-methoxypyridin-2-yl)piperazine-1-carbothioamide (ML267), a potent inhibitor of bacterial phosphopantetheinyl transferase that attenuates secondary metabolism and thwarts bacterial growth. Journal of medicinal chemistry 57:1063-1078. DOI: $10.1021 / \mathrm{jm} 401752 \mathrm{p}$.

Forseth RR, Amaike S, Schwenk D, Affeldt KJ, Hoffmeister D, Schroeder FC, Keller NP 2013. Homologous NRPS-like Gene Clusters Mediate Redundant Small-Molecule Biosynthesis in Aspergillus flavus. Angewandte Chemie (International ed. in English) 52:1590-1594. DOI: 10.1002/anie.201207456.

Fraser DW 1980. LEGIONELLOSIS: EVIDENCE OF AIRBORNE TRANSMISSION. Annals of the New York Academy of Sciences 353:61-66. DOI: 10.1111/j.17496632.1980.tb18906.x.

Fraser DW, Tsai TR, Orenstein W, Parkin WE, Beecham HJ, Sharrar RG, Harris J, Mallison GF, Martin SM, McDade JE, Shepard CC, Brachman PS, Team TFI 2010. Legionnaires' Disease. dx.doi.org 297:1189-1197. DOI: 10.1056/NEJM197712012972201.

Gehring AM, Lambalot RH, Vogel KW, Drueckhammer DG, Walsh CT 1997. Ability of

PeerJ reviewing PDF | (2016:06:11221:2:1:NEW 20 Oct 2016) 
551

552

553

554

555

556

557

558

559

560

561

562

563

564

565

566

567

568

569

570

571

572

573

574

575

576

577

578

579

580

581

582

583

584

585

586

587

588

589

590

591

592

593

594

595

596

Streptomyces spp. aryl carrier proteins and coenzyme A analogs to serve as substrates in vitro for E. coli holo-ACP synthase. Chemistry \& biology 4:17-24. DOI: 10.1016/S10745521(97)90233-7.

Gimenez G, Bertelli C, Moliner C, Robert C, Raoult D, Fournier P-E, Greub G 2011. Insight into cross-talk between intra-amoebal pathogens. BMC genomics 12:542. DOI: 10.1186/14712164-12-542.

Gomez-Valero L, Rusniok C, Jarraud S, Vacherie B, Rouy Z, Barbe V, Médigue C, Etienne J, Buchrieser $C$ 2011. Extensive recombination events and horizontal gene transfer shaped the Legionella pneumophila genomes. BMC genomics 12:536. DOI: 10.1186/1471-2164-12-536.

Guindon S, Dufayard J-F, Lefort V, Anisimova M, Hordijk W, Gascuel O 2010. New algorithms and methods to estimate maximum-likelihood phylogenies: assessing the performance of PhyML 3.0. Systematic biology 59:307-321. DOI: 10.1093/sysbio/syq010.

Gurevich A, Saveliev V, Vyahhi N, Tesler G 2013. QUAST: quality assessment tool for genome assemblies. Bioinformatics (Oxford, England) 29:1072-1075. DOI: 10.1093/bioinformatics/btt086.

Hales LM, Shuman HA 1999. Legionella pneumophila contains a type II general secretion pathway required for growth in amoebae as well as for secretion of the Msp protease. Infection and immunity 67:3662-3666.

Hertweck C 2009. The Biosynthetic Logic of Polyketide Diversity. Angewandte Chemie (International ed. in English) 48:4688-4716. DOI: 10.1002/anie.200806121.

Hoyer KM, Mahlert C, Marahiel MA 2007. The Iterative Gramicidin S Thioesterase Catalyzes Peptide Ligation and Cyclization. Chemistry \& biology 14:13-22. DOI: 10.1016/j.chembiol.2006.10.011.

Igel L, Helbig JH, Lück PC 2004. Isolation and characterization of a nonfluorescent strain of Legionella parisiensis. Journal of clinical microbiology 42:2877-2878. DOI: 10.1128/JCM.42.6.2877-2878.2004.

Isberg RR, O'Connor TJ, Heidtman M 2009. The Legionella pneumophila replication vacuole: making a cosy niche inside host cells. Nature reviews. Microbiology 7:13-24. DOI: 10.1038/nrmicro1967.

Johnston CW, Connaty AD, Skinnider MA, Li Y, Grunwald A, Wyatt MA, Kerr RG, Magarvey NA 2016a. Informatic search strategies to discover analogues and variants of natural product archetypes. Journal of industrial microbiology \& biotechnology 43:293-298. DOI: 10.1007/s10295-015-1675-9.

Johnston CW, Plumb J, Li X, Grinstein S, Magarvey NA 2016b. Informatic analysis reveals Legionella as a source of novel natural products. Synthetic and Systems Biotechnology. DOI: 10.1016/j.synbio.2015.12.001.

Khweek AA, Dávila N, Caution K 2014. Biofilm-derived Legionella pneumophila evades the innate immune response in macrophages. ... Modulation of Host ....

Lechner M, Findeiß S, Steiner L, Marz M, Stadler PF, Prohaska SJ 2011b. Proteinortho : Detection of (Co-)orthologs in large-scale analysis. BMC Bioinformatics 12:124. DOI: 10.1186/1471-2105-12-124.

Liles MR, Scheel TA, Cianciotto NP 2000. Discovery of a nonclassical siderophore, legiobactin, produced by strains of Legionella pneumophila. Journal of bacteriology 182:749-757. DOI: 10.1128/JB.182.3.749-757.2000.

Losick VP, Isberg RR 2006. NF-kappaB translocation prevents host cell death after low-dose challenge by Legionella pneumophila. The Journal of experimental medicine 203:2177- 
597

598

599

600

601

602

603

604

605

606

607

608

609

610

611

612

613

614

615

616

617

618

619

620

621

622

623

624

625

626

627

628

629

630

631

632

633

634

635

636

637

638

639

640

641

642

2189. DOI: $10.1084 /$ jem.20060766.

Minowa Y, Araki M, Kanehisa M 2007. Comprehensive Analysis of Distinctive Polyketide and Nonribosomal Peptide Structural Motifs Encoded in Microbial Genomes. Journal of molecular biology 368:1500-1517. DOI: 10.1016/j.jmb.2007.02.099.

Mofid MR, Finking R, Marahiel MA 2002. Recognition of hybrid peptidyl carrier proteins/acyl carrier proteins in nonribosomal peptide synthetase modules by the 4'-phosphopantetheinyl transferases AcpS and Sfp. Journal of Biological Chemistry 277:17023-17031. DOI: 10.1074/jbc.M200120200.

Mootz HD, Finking R, Marahiel MA 2001. 4'-phosphopantetheine transfer in primary and secondary metabolism of Bacillus subtilis. Journal of Biological Chemistry 276:3728937298. DOI: 10.1074/jbc.M103556200.

Nguyen TMN, Ilef D, Jarraud S, Rouil L, Campese C, Che D, Haeghebaert S, Ganiayre F, Marcel F, Etienne J, Desenclos J-C 2006. A community-wide outbreak of legionnaires disease linked to industrial cooling towers--how far can contaminated aerosols spread? Journal of Infectious Diseases 193:102-111. DOI: 10.1086/498575.

Pagnier I, Croce O, Robert C, Raoult D 2014. Genome sequence of Legionella anisa, isolated from a respiratory sample, using an amoebal coculture procedure. Genome ....

Parsons JB, Rock CO 2011. Is bacterial fatty acid synthesis a valid target for antibacterial drug discovery? Current Opinion in Microbiology 14:544-549.

Polesky AH, Ross JT, Falkow S, Tompkins LS 2001. Identification of Legionella pneumophila genes important for infection of amoebas by signature-tagged mutagenesis. Infection and immunity 69:977-987. DOI: 10.1128/IAI.69.2.977-987.2001.

Rizzardi K, Winiecka-Krusnell J, Ramliden M, Alm E, Andersson S, Byfors S 2015. Legionella norrlandica sp. nov., isolated from the biopurification systems of wood processing plants. International journal of systematic and evolutionary microbiology 65:598-603. DOI: 10.1099/ijs.0.068940-0.

Robey M, Cianciotto NP 2002. Legionella pneumophila feoAB promotes ferrous iron uptake and intracellular infection. Infection and immunity 70:5659-5669. DOI: 10.1128/IAI.70.10.56595669.2002.

Rossier O, Starkenburg SR, Cianciotto NP 2004. Legionella pneumophila type II protein secretion promotes virulence in the A/J mouse model of Legionnaires' disease pneumonia. Infection and immunity 72:310-321. DOI: 10.1128/IAI.72.1.310-321.2004.

Röttig M, Medema MH, Blin K, Weber T, Rausch C, Kohlbacher O 2011. NRPSpredictor2-a web server for predicting NRPS adenylation domain specificity. Nucleic acids research 39:gkr323-W367. DOI: 10.1093/nar/gkr323.

Sadosky AB, Wiater LA, Shuman HA 1993. Identification of Legionella pneumophila genes required for growth within and killing of human macrophages. Infection and immunity 61:5361-5373.

Schlossberg D, Bonoan J 1998. Legionella and immunosuppression. Seminars in respiratory infections 13:128-131.

Scholz-Schroeder BK, Soule JD, Gross DC 2007. The sypA, sypB, and sypC Synthetase Genes Encode Twenty-Two Modules Involved in the Nonribosomal Peptide Synthesis of Syringopeptin by Pseudomonas syringae pv. syringae B301D. dx.doi.org 16:271-280. DOI: 10.1094/MPMI.2003.16.4.271.

Seemann T 2014. Prokka: rapid prokaryotic genome annotation. Bioinformatics (Oxford, England) 30:2068-2069. DOI: 10.1093/bioinformatics/btu153. 
643 Segal G, Shuman HA 1998. Intracellular multiplication and human macrophage killing by

644

645

646

647

648

649

650

651

652

653

654

655

656

657

658

659

660

661

662

663

664

665

666

667

668

669

670

671

672

673

674

675

676

677

678

679

680

681

682

683

684

685

686

687

688

Legionella pneumophila are inhibited by conjugal components of IncQ plasmid RSF1010.

Molecular microbiology 30:197-208.

Seidle HF, Couch RD, Parry RJ 2006. Characterization of a nonspecific phosphopantetheinyl transferase from Pseudomonas syringae pv. syringae FF5. Archives of biochemistry and biophysics 446:167-174.

Shaw-Reid CA, Kelleher NL, Losey HC, Gehring AM, Berg C, Walsh CT 1999. Assembly line enzymology by multimodular nonribosomal peptide synthetases: the thioesterase domain of E. coli EntF catalyzes both elongation and cyclolactonization. Chemistry \& biology 6:385400. DOI: 10.1016/S1074-5521(99)80050-7.

Shevchuk O, Pägelow D, Rasch J, Döhrmann S, Günther G, Hoppe J, Ünal CM, Bronietzki M, Gutierrez MG, Steinert M 2014. Polyketide synthase (PKS) reduces fusion of Legionella pneumophila-containing vacuoles with lysosomes and contributes to bacterial competitiveness during infection. International Journal of Medical Microbiology 304:11691181. DOI: $10.1016 /$ j.ijmm.2014.08.010.

Sieber SA, Marahiel MA 2005. Molecular Mechanisms Underlying Nonribosomal Peptide Synthesis: Approaches to New Antibiotics. Chemical Reviews 105:715-738. DOI: $10.1021 /$ cr0301191.

Silver LL 2007. Multi-targeting by monotherapeutic antibacterials. Nature Reviews Drug Discovery 6:41-55. DOI: $10.1038 / \mathrm{nrd} 2202$.

Söderberg MA, Rossier O, Cianciotto NP 2004. The type II protein secretion system of Legionella pneumophila promotes growth at low temperatures. Journal of bacteriology 186:3712-3720. DOI: 10.1128/JB.186.12.3712-3720.2004.

Stachelhaus T, Mootz HD, Marahiel MA 1999. The specificity-conferring code of adenylation domains in nonribosomal peptide synthetases. Chemistry \& biology 6:493-505. DOI: 10.1016/S1074-5521(99)80082-9.

Stack D, Neville C, Doyle S 2007. Nonribosomal peptide synthesis in Aspergillus fumigatus and other fungi. Microbiology 153:1297-1306. DOI: 10.1099/mic.0.2006/006908-0.

Stamatakis A 2014. RAxML version 8: a tool for phylogenetic analysis and post-analysis of large phylogenies. Bioinformatics (Oxford, England) 30:1312-1313. DOI: 10.1093/bioinformatics/btu033.

Stinear TP, Mve-Obiang A, Small PLC, Frigui W, Pryor MJ, Brosch R, Jenkin GA, Johnson PDR, Davies JK, Lee RE, Adusumilli S, Garnier T, Haydock SF, Leadlay PF, Cole ST 2004. Giant plasmid-encoded polyketide synthases produce the macrolide toxin of Mycobacterium ulcerans. Proceedings of the National Academy of Sciences 101:1345-1349. DOI: 10.1073/pnas.0305877101.

Thacker WL, Benson RF, Hawes L, Gidding H, Dwyer B, Mayberry WR, Brenner DJ 1991. Legionella fairfieldensis sp. nov. isolated from cooling tower waters in Australia. Journal of clinical microbiology 29:475-478.

Thacker WL, Dyke JW, Benson RF, Havlichek DH, Robinson-Dunn B, Stiefel H, Schneider W, Moss CW, Mayberry WR, Brenner DJ 1992. Legionella lansingensis sp. nov. isolated from a patient with pneumonia and underlying chronic lymphocytic leukemia. Journal of clinical microbiology 30:2398-2401.

Verma UK, Brenner DJ, Thacker WL, Benson RF, Vesey G, Kurtz JB, Dennis PJL, Steigerwalt AG, Robinson JS, Moss CW 1992. Legionella shakespearei sp. nov., Isolated From Cooling Tower Water. International journal of systematic and evolutionary microbiology 42:404- 
689

690

691

692

693

694

695

696

697

698

699

700

701

702

703

704

705

706

707

708

709

710

711

712

407. DOI: $10.1099 / 00207713-42-3-404$.

Walsh CT, Gehring AM, Weinreb PH, Quadri LE, Flugel RS 1997. Post-translational modification of polyketide and nonribosomal peptide synthases. Current opinion in chemical biology 1:309-315. DOI: 10.1016/S1367-5931(97)80067-1.

Weber T, Blin K, Duddela S, Krug D, Kim HU, Bruccoleri R, Lee SY, Fischbach MA, Müller R, Wohlleben W, Breitling R, Takano E, Medema MH 2015b. antiSMASH 3.0-a comprehensive resource for the genome mining of biosynthetic gene clusters. Nucleic acids research 43:W237-43. DOI: 10.1093/nar/gkv437.

Wilkinson HW, Drasar V, Thacker WL, Benson RF, Schindler J, Potuznikova B, Mayberry WR, Brenner DJ 1988. Legionella moravica sp. Nov. and Legionella brunensis sp. Nov. Isolated from cooling-tower water. Annales de l'Institut Pasteur / Microbiologie 139:393-402. DOI: 10.1016/0769-2609(88)90102-0.

Yadav G, Gokhale RS, Mohanty D 2003. Computational Approach for Prediction of Domain Organization and Substrate Specificity of Modular Polyketide Synthases. Journal of molecular biology 328:335-363.

Yang S-C, Lin C-H, Sung CT, Fang J-Y 2014. Antibacterial activities of bacteriocins: application in foods and pharmaceuticals. Frontiers in Microbiology 5:12. DOI: 10.3389/fmicb.2014.00241.

Yao J, Abdelrahman YM, Robertson RM, Cox JV, Belland RJ, White SW, Rock CO 2014. Type II fatty acid synthesis is essential for the replication of Chlamydia trachomatis. The Journal of biological chemistry 289:22365-22376. DOI: 10.1074/jbc.M114.584185. 
713 Figure 1. Structures of the known Legionella natural products legioliulin, legionellol and 714 legiobactin as well as PPTase inhibitor used in this study (4-6).

715<smiles>O=c1oc(/C=C/C=C/c2ccccc2)cc2cccc(O)c12</smiles><smiles>CCCCC(O)C(O)C(O)C(CO)C(C)(C)c1ccccc1OC(CN)C(O)C(N)CO</smiles>

Legionellol A (2)

(L. pneumophila)<smiles>O=C(O)CC(O)(CO)CC(=O)NCCCCNC(=O)CC(O)(CO)C(=O)O</smiles>

Legiobactin (3)

(L. pneumophila)

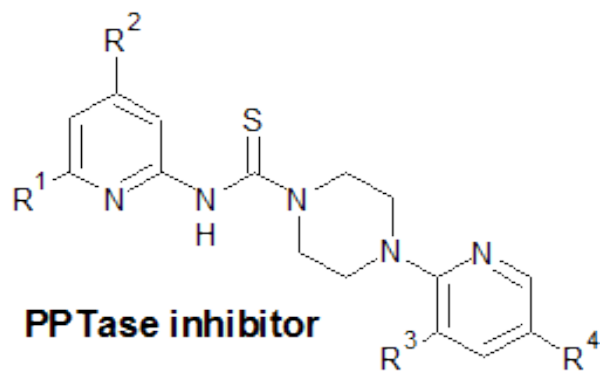

\begin{tabular}{lllll} 
& $\mathrm{R}^{1}$ & $\mathrm{R}^{2}$ & $\mathrm{R}^{3}$ & $\mathrm{R}^{4}$ \\
\hline $\mathbf{4}$ & $\mathrm{H}$ & $\mathrm{OMe}$ & $\mathrm{Cl}$ & $\mathrm{CF}_{3}$ \\
$\mathbf{5}$ & $\mathrm{H}$ & $\mathrm{Me}$ & $\mathrm{CF}_{3}$ & $\mathrm{H}$ \\
$\mathbf{6}$ & $\mathrm{Me}$ & $\mathrm{Me}$ & $\mathrm{CF}_{3}$ & $\mathrm{Cl}$
\end{tabular}


718 Figure 2. Legionella phylogeny based on presence or absence of ortholog families together with 719 a summary of orthologous BGCs found in two or more Legionella species. BGCs were identified 720 using antiSMASH (Weber et al., 2015b) and nucleotide sequences were aligned using Mauve

721 (Darling et al., 2004) to determine those that were similar. Ortholog presence was first

722 determined using proteinortho5 (Lechner et al., 2011a). The gene content tree was then

723 constructed using RAxML, based on the presence or absence of each ortholog. BGCs are

724 separated according to the class of compound produced. Cluster letters refer to those genetic

725 schematics shown in Figure 3 and compound numbers refer to those found in Figures $1 \& 6$. A

726 full list of BGCs can be found in Supplementary Table 3. The gene cluster encoding IsnAB is not

727 detected by antiSMASH but is a known BGC responsible for the biosynthesis of isonitrile

728 containing compounds that are widespread in bacteria (Brady et al., 2007).

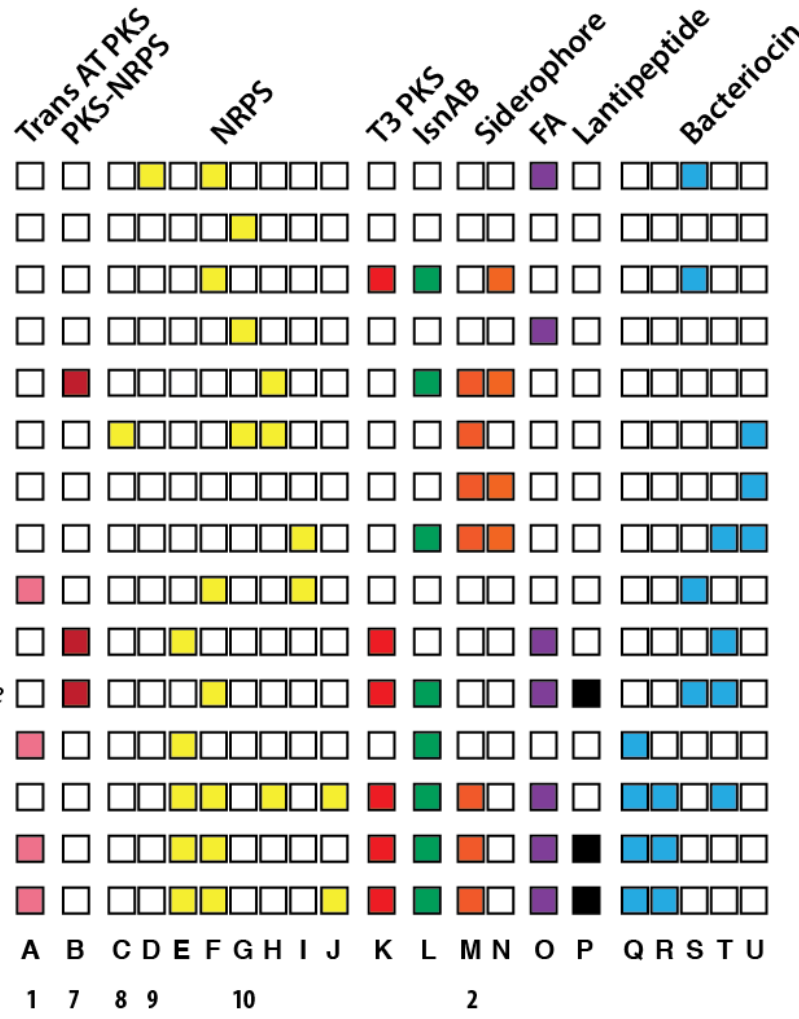


Figure 3. Representative examples of BGCs found in multiple Legionella species as identified in Figure 2. Protein domain architecture as determined from NCBI's conserved domain database for NRPS (green) and PKS (red) encoding genes are also shown. Each circle represents an individual domain of the respective PKS or NRPS (domains not to scale). The PKS from L. pneumophila (I) contains a C-terminal condensation domain typical of those seen in NRPSs, which is also capable of polyketide chain release. Clusters $\mathrm{O}-\mathrm{U}$ can be found in Supplementary Figure 1. All clusters are in Supplementary Table 3.
A L. cherii
Q775_RS0106140

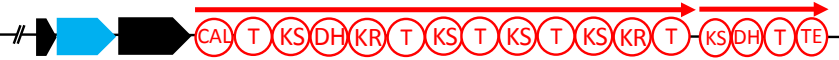
HI Q775_RS17345
B L. longbeachae LLO_RS17435
-I -A)(TSSATRR(T) TIE.
C L. moravica
G543_RS18230

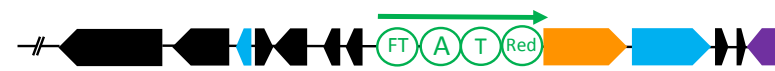
H. $\rightarrow$ G543_RS0100855
D L.fairfieldensis T345_RS0111855

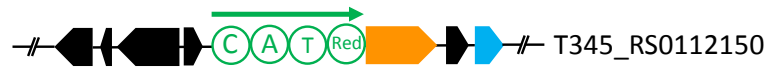
E L.wadsworthii BU07_RS0101930
\#- $\rightarrow$ A C $\rightarrow$ BU07_RS0101750
F L. longbeachae LLO_RS11405
- $\overrightarrow{-A(\mathrm{~A})} \quad$ H LLO_RS11230
G L. moravica
G543_RS0102490
\#-
H/ G543_RS0102670
H L. moravica
G543_RS01130
$\rightarrow$ - A) (T)
L. pneumophila Ipg2152
J. Ladsworthii BU07_RS0101545

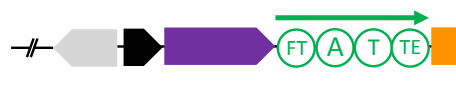
- A A A
IAC(
K L. longbeachae LLO_RS08165

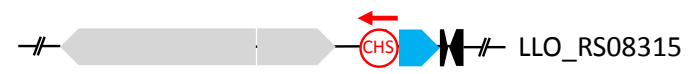
L L. parisiensis Ipari_01859
isnA isnB
M L. moravica G543_RS0106200
આ-D - - C G543_RS0106305
N L. lansingensis BU01_RS0106700
-1

Accessory biosynthetic enzyme PKS

Other

Hypothetical

NRPS

Regulatory

Transporter

Siderophore biosynthesis protein

C) Condensation

A Adenylation

(Red) Reductase

FT) Formyltransferase

(A) Coenzyme A ligase

(KS) Ketosynthase

(AT) Acyltransferase

(KR) Ketoreductase

(D) Dehydratase

(CHS) Chalcone synthase

(TE) (TE) Thioesterase

(T) Thiolation

$2,000 \mathrm{bp}$ 
737 Figure 4. Maximum likelihood phylogeny created using PhyML of PPTases identified in

738 Legionella genomes and their relationship to a selection of PPTases from other bacteria. Scale

739 represents amino acid substitutions per amino acid position. Bootstrapping $(\mathrm{n}=1000)$ was used to 740 support branch formation. 


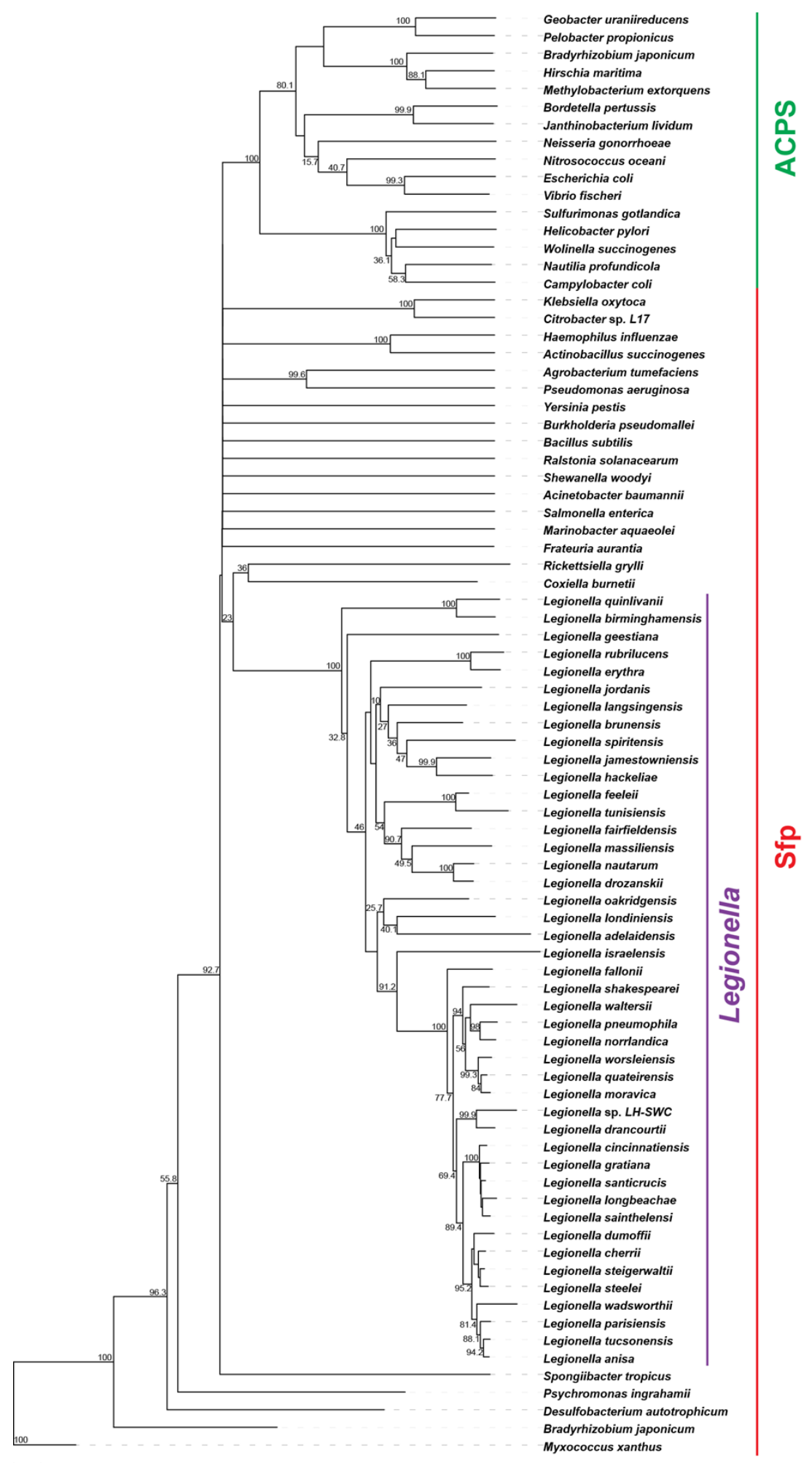

$741 \quad 0.1$

742 Figure 5. Inhibition of legioliulin production resulting in fluorescence (at $366 \mathrm{~nm}$ ) in $L$. 
743 parisiensis by PPTase inhibitors 4-6.

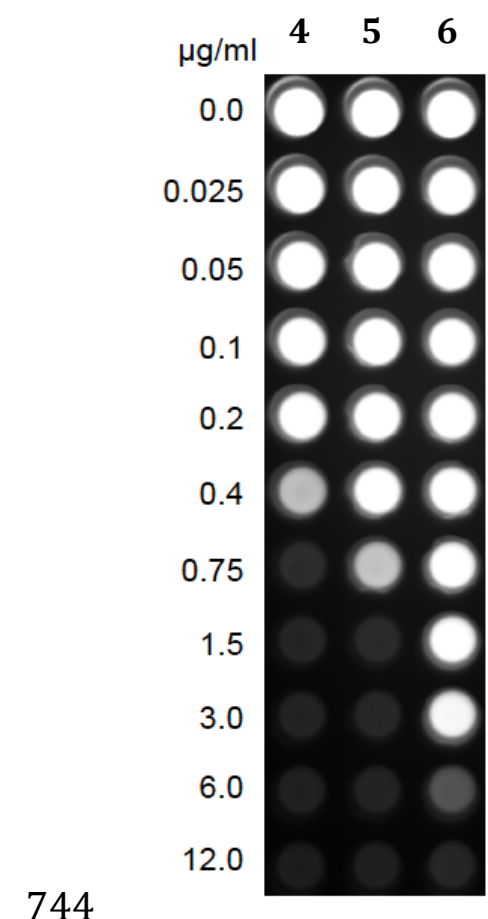

744

745

746

747 
748 Figure 6. Theoretical structures of compounds 7-10 predicted from the clusters B-D, G and I

749 (monomodular NRPS), shown in Figure 2. Monomodular NRPS are predicted to produce

750 modified amino acids or dipeptide derivatives that have also been identified in different fungi

751 (Forseth et al., 2013). In a relatively rarely described phenomenon, NRPS domains may be re-

752 used during product biosynthesis resulting in peptides longer than expected from the NRPS

753 domain architecture. An example of such an iterative use is due to the action of the thioesterase

754 domain which, following a single round of biosynthesis, must oligomerize the enzyme bound

755 peptide product before release from the NRPS (Shaw-Reid et al., 1999; Bruner et al., 2002;

756 Hoyer, Mahlert \& Marahiel, 2007; Felnagle et al., 2008). Due to the relative infrequency that this

757 happens, we assumed non-iterative use of domains for all structural predictions. Cluster B

758 (Figure 3) encodes a NRPS/PKS hybrid that is suggested to produce a valine elongated by a

759 single polyketide elongation using malonyl-CoA with the resulting product, dependent on the

760 thioesterase (TE) function, might be linear (7a) or cyclic (7b). Cluster C encodes a monomodular

761 NRPS that is predicted to produce a $N$-formylated amino acid that is either reduced by the C-

762 terminal reduction (Red) domain to the aldehyde (8a), or the alcohol $(\mathbf{8 b})$ that can then by

763 cyclized non-enzymatically to form an oxazoline ring $(\mathbf{8 c})$. The acylated amino acid derived

764 from cluster D can undergo similar transformation resulting in structurally related compounds

$765(9 \mathbf{a}, 9 \mathbf{b}, 9 \mathbf{9})$. Cluster $\mathrm{G}$ and I are very similar to $\mathrm{C}$ but the NRPS is terminated by a TE domain

766 resulting again in either a linear (10a) or cyclic product (10b).

767 
B<smiles>CC(C)[C@H](N)C(O)CC(=O)O</smiles><smiles>CC(C)[C@H]1NC(=O)CC1O</smiles>

C<smiles>[R][C@H](C=O)NC=O</smiles><smiles>[R][C@H](CO)NC=O</smiles><smiles>[R]C1COC=N1</smiles>

D<smiles>[R]C(=O)N[C@@H](C)C=O</smiles><smiles>[R]C(=O)N[C@@H](C)CO</smiles><smiles>[R]C1=N[C@@H](C)CO1</smiles>

$\mathbf{G} / \mathbf{I}$<smiles>[R][C@H](NC=O)C(=O)O</smiles><smiles>[R]C1N=COC1=O</smiles> 
769 Table 1. All genome details for Legionella spp. used in this study.

\begin{tabular}{|c|c|c|c|}
\hline Species & Genome Accession No. & Source & Reference \\
\hline Legionella anisa str. Linanisette & NZ_CANP00000000.1 & Clinical sample & (Pagnier et al., 2014) \\
\hline Legionella cherrii DSM19213 & NZ_JHYM00000000.1 & $\begin{array}{c}\text { Thermally altered } \\
\text { water }\end{array}$ & (Brenner et al., 1985) \\
\hline Legionella drancourtii LLAP12 & NZ_ACUL00000000.2 & $\begin{array}{l}\text { Environmental } \\
\text { water source }\end{array}$ & (Gimenez et al., 2011) \\
\hline Legionella fairfieldensis ATCC49588 & NZ_JHYC00000000.1 & Cooling tower & (Thacker et al., 1991) \\
\hline Legionella geestiana DSM21217 & NZ_JHYN00000000.1 & $\begin{array}{l}\text { Domestic hot } \\
\text { water }\end{array}$ & (Dennis et al., 1993) \\
\hline Legionella lansingensis DSM19556 & NZ_JHWF00000000.1 & Clinical sample & (Thacker et al., 1992) \\
\hline Legionella longbeachae NSW150 & NC_013861.1, NC_014544.1 & Clinical sample & (Cazalet et al., 2010) \\
\hline Legionella moravica DSM19234 & NZ_AUHS00000000.1 & Cooling tower & (Wilkinson et al., 1988) \\
\hline Legionella norrlandica strain LEGN & NZ_JNCF00000000.1 & $\begin{array}{l}\text { Biopurification } \\
\text { system of wood } \\
\text { processing plant }\end{array}$ & (Rizzardi et al., 2015) \\
\hline Legionella oakridgensis ATCC33761 & NZ_CP004006.1, NZ_CP004007.1 & Cooling tower & (Brzuszkiewicz et al., 2013) \\
\hline $\begin{array}{l}\text { Legionella pneumophila subsp. } \\
\text { pneumophila str. Philadelphia } 1\end{array}$ & NC_002942.5 & Clinical sample & (Chien et al., 2004) \\
\hline Legionella sainthelensis ATCC 35248 & NZ_JHXP00000000.1 & Surface water & (Campbell et al., 1984) \\
\hline Legionella shakespearei DSM23087 & NZ_AREN00000000.1 & Cooling tower & (Verma et al., 1992) \\
\hline Legionella wadsworthii DSM21896 & NZ_JNIA00000000.1 & Clinical isolate & (Edelstein et al., 1982) \\
\hline Legionella parisiensis DSM19216 & LSOG00000000 & Cooling tower & This study \\
\hline
\end{tabular}

